\title{
Natural orifice surgery: new concept in minimally invasive surgery
}

\author{
Cirurgia por orifícios naturais: novo conceito em cirurgia minimamente invasiva
}

Thomaz Rafael Gollop ${ }^{1}$, Arnaldo Urbano Ruiz Filho ${ }^{2}$, Adriana Grandesso dos Santos 3 , Rogério Francisco Bianchi Alexandre Guilherme Zabeu Rossi ${ }^{5}$

\begin{abstract}
We present the concept of natural orifice surgery and of scarless operations, with their access routes, their multidisciplinary character, and challenges to their development. We point out the intra- and postoperative advantages. We emphasize the use of the vaginal route and posterior colpotomy in the application of natural orifice surgery in vaginal hysterectomies and surgical access to adnexa, which includes tubal ligation. We highlight the need for mastering these surgical modalities, which can bring great advantages to patients in Brazil.
\end{abstract}

Keywords: Surgical procedures, minimally invasive; Colpotomy; Hysterectomy, vaginal; Sterilization, tubal; Ovarian cysts

\section{RESUMO}

Apresentamos, neste artigo, o conceito das cirurgias por orifícios naturais e das cirurgias "sem cicatriz", as suas vias de acesso, seu caráter multidisciplinar e os desafios de seu desenvolvimento. Apontamos as vantagens intra e pós-operatórias. Enfocamos a via vaginal e a colpotomia posterior na aplicação das cirurgias por orifícios naturais em histerectomias vaginais e acessos cirúrgicos aos anexos nos quais se inclui a laqueadura tubárea. Reforçamos a necessidade de nos inteirarmos destas modalidades de cirurgia que poderão trazer grandes vantagens para as pacientes no Brasil.

Descritores: Procedimentos cirúrgicos minimamente invasivos; Colpotomia; Histerectomia vaginal; Esterilização tubária; Cistos ovarianos
The search for low-cost minimally invasive procedures has been underway since the $19^{\text {th }}$ century ${ }^{(1)}$.

Surgery performed through natural orifices (NOS) refers to access routes through the orifices that already exist in the human body, such as the vagina, the oral cavity, or via organs such as the stomach through which operations may be performed, thus avoiding external incisions. NOS includes transgastric, transuterine, transurethral, transanal, and through Douglas cul-desac approaches. The NOS represent a new concept that will revolutionize intra-abdominal surgery. Clearly, the major objectives in this type of surgical access are: to minimize trauma, to promote quicker patient recovery, and to decrease postoperative pain and hospital costs.

\section{THEORETICAL ADVANTAGES OF THE NATURAL ORIFICE SURGERY}

Intraoperative:

- introduction of surgical instruments in parallel, not perpendicularly, to the major retroperitoneal vessels (as with trocars in laparoscopic operations);

- lower $\mathrm{CO}_{2}$ pressure or absence of the need for pneumoperitoneum;

- more ergonomic surgery;

- possibility of using larger caliber instruments than those used in laparoscopy.

Postdoctorate degree; Adjunct professor of Gynecology of Faculdade de Medicina de Jundiaí - Jundiaí (SP), Brazil; Head of the Group of Vaginal and Pelvic Floor Surgery of Centro de Referência de Saúde da Mulher of Hospital Pérola Byington - São Paulo (SP), Brazil; Medical staff of Hospital Israelita Albert Einstein - HIAE, São Paulo (SP), Brazil.

${ }^{2}$ General surgeon at Centro de Referência de Saúde da Mulher of Hospital Pérola Byington - São Paulo (SP), Brazil; Medical staff of Hospital Israelita Albert Einstein - HIAE, São Paulo (SP), Brazil.

${ }^{3} \mathrm{MD}$; Training physician of the Group of Vaginal and Pelvic Floor Surgery of Centro de Referência de Saúde da Mulher of Hospital Pérola Byington - São Paulo (SP), Brazil.

${ }^{4}$ MD; Group of Vaginal and Pelvic Floor Surgery of Centro de Referência de Saúde da Mulher of Hospital Pérola Byington - São Paulo (SP), Brazil; Medical staff of Hospital Israelita Albert Einstein - HIAE, São Paulo (SP), Brazil.

${ }^{5}$ PhD; Group of Vaginal and Pelvic Floor Surgery of Centro de Referência de Saúde da Mulher of Hospital Pérola Byington - São Paulo (SP), Brazil; Medical staff of Hospital Israelita Albert Einstein - HIAE, São Paulo (SP), Brazil. 
Postoperative:

- lower costs;

- possibility of performing procedures in simple locations, without many resources, generating greater satisfaction for patients and physicians;

- lower risk of herniation;

- minimal risk of eventration;

- lower risk of surgical scar infection;

- lower risk of adherences;

- less postoperative pain.

\section{CHALLENGES FOR NATURAL ORIFICE SURGERY}

Since it is a new surgical approach, one could say that it is rapidly being incorporated in First World countries, but there is a series of steps that need to be accomplished, such as:

- development of adapted instruments and specific surgical techniques;

- resolution of physiological problems (acidity, sterilization, stomach sutures etc);

- acquisition of surgical training and experience.

We should point out that the New European Surgical Academy (NESA), whose current president is Prof. Michael Stark, creator of the minimally invasive C-section ${ }^{(2)}$, is an excellent training center and exchanges experiences with several other countries. As per the policy of NESA itself, there is great interest in training professionals in developing countries. Our group is affiliated with NESA and is motivated to exchange experiences with other institutions in our country.

\section{DEVELOPMENT OF INSTRUMENTS ADAPTED FOR NATURAL ORIFICE SURGERY}

Currently, the training of surgeons can be done by incorporating electronic information technology resources and simulators. At the centers where NOS is being introduced, there is a concern for developing:

- dependable simulation programs for training and research;

- multichannel and flexible endoscopes and gastroscopes;

- "U" and "S"-shaped flexible and rigid endoscopes with possible robotic command.

\section{"SCARLESS" OPERATIONS}

"Scarless" operations (SLO) are safe alternatives to traditional operations. They enable the avoidance of visible scars. There are several examples, such as endoscopic extraperitoneal correction of inguinal hernias, transanal endoscopic microsurgery, videoendoscopic thyroidectomy via bilateral axillary-mammary access, transumbilical herniorrhaphy, transoral thyroidectomy, etc. One example of sophistication, in order to give some perspective of the future possibilities of this technology, is the description of Asao et al. (2005) $)^{(3)}$ of videoscopic thyroidectomy with equipment monitoring fine needles through which the operation leaves no scars on the neck.

\section{EQUIPMENT UTILIZED OR TO BE DEVELOPED FOR NOS OR "SCARLESS" OPERATIONS}

- Focused ultrasound.

- Radiofrequency.

- Cryosurgery.

- Laser.

- Electrical coagulation.

- Microwave therapy.

One interesting aspect of NOS and "scarless" surgery is the need for interdisciplinary cooperation, since surgical procedures, such as an appendectomy, may come to be performed via "gynecological" (cul-desac of Douglas) accesses, and gynecological procedures may come to be conducted through "surgical" access routes.

\section{NATURAL ORIFICE SURGERY: IMMEDIATE APPLICATION IN BRAZIL}

\section{Vaginal hysterectomy of a nonprolapsed uterus}

This is a NOS situation, par excellence, besides being the least invasive approach for the surgical removal of uteri $^{(4)}$. Despite the existence of medical training courses for vaginal hysterectomies of the nonprolapsed uterus (VH) for more than eight years, its practical application in our country is still very restricted. The vaginal route is limited to benign pathologies and its use is excluded when there is suspected pelvic endometriosis. Nevertheless, there is a significant discussion to be had as to the adaptation of our social-economic reality in Brazil: we urgently need to reduce hospital costs and benefit our patients with minimally invasive techniques that use fewer analgesics, reduce hospital stay and febrile and infective morbidity, thus allowing them to return to normal activities as quickly as possible.

Currently, many hysterectomies are carried out via videolaparoscopy ( $\mathrm{VH})$ or they are laparoscopy-assisted vaginal hysterectomies (LAVH), even in cases of large uteri $^{(5)}$. In a prospective randomized study, no differences were found between VH and LAVH as to blood loss, complications, hospital stay, and convalescence period. The costs of LAVH, however, are considerably lower ${ }^{(6)}$.

One must also consider that $\mathrm{VH}$ always uses permanent materials, and in a pilot project we are 
introducing at Hospital Pérola Byington (SUS), São Paulo, we have operated patients with precise clinical indications, most of them with a clinical history of hypermenorrhea and voluminous uteri who, once hospitalized and submitted to $\mathrm{VH}$, are discharged within 24 hours after the procedure in amazing clinical conditions. The analysis of these data is being prepared for a future publication.

In this way, it is important to highlight that $\mathrm{VH}$ should always be considered as an access route when hysterectomy is indicated for a benign pathology, due to its rapid recovery, absence of abdominal scars of any nature, short hospital stay, and lower $\operatorname{costs}^{(7,8)}$. In international medical literature there are increasingly fewer contraindications for $\mathrm{VH}$, and this access route should be applied in nulliparous patients, those with prior C-sections, and those with large uteri ${ }^{(9)}$. A recent Cochrane review concluded that the best approach for hysterectomy in benign diseases of the uterus is that performed vaginally ${ }^{(10)}$.

We believe that is fundamental that $\mathrm{VH}$ be incorporated more frequently in our therapeutic arsenal, benefiting patients of all social classes and mimicking what is being done in other countries.

\section{VAGINAL ADNEXAL OPERATIONS}

Access to uterine adnexa is extremely simple through posterior colpotomy. Evidently, this is an access that necessarily involves confirmed benign pathologies. Oophorectomy and oophoroplasty, as well as tubal ligation, may be performed by this route and the learning curve for an experienced gynecologist is not prolonged. It is important to remember that adnexectomy is also viable during $\mathrm{VH}$ in $95 \%$ of the cases ${ }^{(11)}$.

It is amazing to see how public or private hospitals have hundreds of patients submitted to tubal ligation by laparotomy or videolaparoscopy. However, this approach may be even simpler by the vaginal route, with an extremely high success rate. It benefits patients and costs the healthcare system a lot less. This can be seen in some centers in Europe, such as Italy, where the approach to benign adnexal tumors is done vaginally ${ }^{(12)}$.

In this article, we presented a summarized reference to some applications of NOS and SLO, in other words, the most well-known in Brazil. This is fertile land, and the applications of these techniques will grow, stimulating a series of future projects.

\section{REFERENCES}

1. [No authors listed]. Classic pages in obstetrics and gynecology. Vaginal ovariotomy. American Journal of the Medical Sciences, vol. 59, pp. 387-390. Am J Obstet Gynecol. 1974;119(7):995.

2. Gollop TR. Nova técnica de cesárea. Femina. 2004;32(8):705-7.

3. AsaoT,KuwanoH, YamaguchiS, UchidaN, YanagitaY. Videoscopic thyroidectomy with fine needle-type apparatuses: an approach that does not leave a scar on the neck or anterior chest. Surg Laparosc Endosc Percutan Tech. 2005; 15(6):339-44.

4. Moen MD, Noone MB, Elser DM; Urogynecology Network. Natural orifice hysterectomy. Int Urogynecol J Pelvic Floor Dysfunct. 2008;19(9):1189-92. Epub 2008 Jun 11.

5. Schütz K, Possover M, Merker A, Michels W, Schneider A. Prospective randomized comparison of laparoscopic-assisted vaginal hysterectomy (LAVH) with abdominal hysterectomy $(\mathrm{AH})$ for the treatment of the uterus weighing $>200$ g. Surg Endosc. 2002;16(1):121-5.

6. Summitt RL Jr, Stovall TG, Lipscomb GH, Ling FW. Randomized comparison of laparoscopy-assisted vaginal hysterectomy with standard vaginal hysterectomy in an outpatient setting. Obstet Gynecol. 1992;80(6): 895-901.

7. Kalogirou D, Antoniou G, Zioris C, Fotopoulos S, Karakitsos P. Vaginal hysterectomy: technique and results in the last twenty years. J Gynecol Surg. 1995;11(4):201-7

8. Cravello L, Bretelle F, Cohen D, Roger V, Giuly J, Blanc B. [Vaginal hysterectomy: apropos of a series of 1008 interventions]. Gynecol Obstet Fertil. 2001;29(4):288-94.

9. Taylor SM, Romero AA, Kammerer-Doak DN, Qualls C, Rogers RG. Abdominal hysterectomy for the enlarged myomatous uterus compared with vaginal hysterectomy with morcellation. Am J Obstet Gynecol. 2003;189(6): 1579-82.

10. Nieboer TE, Johnson N, Lethaby A, Tavender E, Curr E, Garry R, et al. Surgical approach to hysterectomy for benign gynaecological disease. Cochrane Database Syst Rev. 2009; (3):CD003677.

11. Sheth SS. Adnexectomy for benign pathology at vaginal hysterectomy without laparoscopic assistance. BJOG. 2002;109(12):1401-5.

12. Massi GB, Savino L, Lena A, Susini T. Management of benign adnexal masses by vaginal route. Front Biosci. 1996;1:g8-11. 